\title{
Cost implications of no-fault automobile insurance
}

By: Joseph E. Johnson, George B. Flanigan, and Daniel T. Winkler

Johnson, J. E., G. B. Flanigan, and D. T. Winkler. "Cost Implications of No-Fault Automobile Insurance," The Journal of Risk and Insurance, March 1992, pp. 116-123.

Made available courtesy of Blackwell Publishing:

http://www.wiley.com/bw/journal.asp?ref=0022-4367

\section{The definitive version is available at www.blackwell-synergy.com}

\begin{abstract}
:
No fault advocates commonly predict automobile insurance cost savings for consumers in states adopting no-faults statutes in place of a tort system. For states implementing no-fault, the cost results have been mixed. This study compares the loss costs of no-fault from 1974 through 1985. Not surprisingly, the findings suggest that the bodily injury liability loss costs were lower on average in no-fault states than in tort states after controlling for the influence of wages, population density, and the presence of comparative negligence. However, total bodily injury related costs were not significantly lower on average in no-fault states, and they were significantly higher in states with compulsory add-on laws and to a lesser extent in states with high tort thresholds. Whether the lack of estimated cost savings on average in no-fault states in attributable to selection bias or not, the causes of this result are important issues for further research.
\end{abstract}

\section{Article:}

No fault has again become a subject of debate following several years of inactivity. Leading advocates of the adoption of new no-fault law, or modification of current statutes to further restrict tort remedy, are predominantly insurance companies and some consumer groups. Opponents of no-fault reform are principally members of the trial bar. Over the period of 1971 to 1987, 24 states plus the District of Columbia and Puerto Rico adopted forms of no-fault. Very little movement towards no-fault took place after the mid 1970s aside from a few states changing their tort thresholds and Pennsylvania moving from low thresholds no-fault toward a compulsory add-on-no-fault.(1)

The question of whether no-fault laws reduce the cost of automobile insurance remains unsettled. A report by the Department of Transportation (1985) suggests that cost savings result from nofault, and compulsory add-on results in higher cost than no tort or no-fault. The DOT study, however, did not control for some important causal factors. Johnson, Flanigan and Weeks (1983) found that cost savings were not present under no-fault. They failed to differentiate between certain types of no-fault and did not control for individual state effects. A recent study by Smith (1989) compares the projected cost of automobile reparations for no-faults states had they remained fault and argues that some no-fault laws have produced significant cost savings. Smith relies upon opinions of what a claim would have been under different assumptions. Problems and limitations of this approach are discussed by Todd (1976). 
The purpose of this study is to measure average automobile insurance costs under different automobile reparations systems. This study employs actual insurance loss cost data over the period 1974 to 1985 in a multi-variate context. Analysis of loss cost data does not support the hypothesis that no-fault systems have had lower costs than fault systems when all automobile insurance costs for bodily injury are included. The possibility of selection bias is briefly discussed in the concluding section.

\section{Research Methods and Data}

Total system (i.e. bodily injury related) loss costs for automobile reparations consists of losses covered by bodily injury liability, medical payments, uninsured motorist, and personal injury protection insurance. The loss of concept incorporates both frequency and severity. The database is constructed from annual data compiled by the Insurance Service Office (ISO) for both voluntary and residual markets. The data are incurred losses, including loss adjustment expenses, on an earned car year basis. Forty seven of the 50 states are included for the period 1974 through 1985 (Massachusettes, South Carolina, and Texas did not report to the ISO).

Reparations systems were categorized into six classes: verbal threshold, high threshold, low threshold, optional add-on no-fault, compulsory add-on no-fault and tort states. Each classification is briefly described below:

1. Verbal: Injured party actions are barred except when permanent injury, death, or disfigurement results or when economic losses are uncompensated. No-fault advocates allege that verbal is the least cost alternative (Smith, 1989).

2. High threshold: Injured party actions are barred except when the dollar amount of their economic losses exceeds a relatively high specified amount. Thresholds of more than $\$ 1,000$ are considered high.(2)

3. Low threshold: Injured party actions are barred except when the dollar amount of economic losses exceeds a relatively low specified amount. Thresholds of less than or equal to $\$ 1,000$ are considered low.

4. Compulsory add-on: The tort system is retained but no-fault benefits are compulsorily included.

5. Optional add-on" Policy holders must be offered the opportunity to purchase optional add-on no-fault benefits with no changes in the underlying tort liability system.

6. Tort: No limitations on the right to seek recovery in tort and no compulsory or optional addon no-fault benefits.

The analysis considers 12 years of loss experience by state as classified above beginning in 1974 . The tested hypothesis is that no-fault systems have lower average per car loss costs than does the tort system. No-fault systems would be less expensive if the total system loss costs were lower under no-fault than tort, controlling for extraneous influences.

\section{Regression Analysis}

Multiple regression is used to compare the cost of each no-fault classification to the cost of tort holding constant independent factors. The independent variables are contributory negligence or comparative negligence, population per square mile, and manufacturing wages. 
Flanigan, et. al. (1989) found that comparative negligence states have higher loss costs than contributory negligence states because plaintiffs are able to recover when partially at fault. The plaintiff must be free of fault in contributory negligence states. Population per square mile captures the effects of greater vehicular traffic congestion and consequent accidents.

Manufacturing wages are used as a proxy for wage and price level difference among states. Automobile loss costs are influenced by many components which clearly differ among states and over time. For example, medical care costs, disability income loss, the cost of processing claims, and legal fees influence loss costs. A consumer price index by state is not available. The use of this proxy is supported by the fact of mobility in the labor force calibrating wages with the cost of living over time.(3)

The regression analysis applies a covariance model and an error components model (Fuller and Battese, 1974) which are commonly used regression techniques for time-series-cross-sectional data analysis.(4) The findings are reported utilizing both models.

\section{Results}

Table 1 presents the OLS, covariance, and Fuller-Battese error components model regression with the dependent variable BI (bodily injury costs) and independent variables for no-fault system, negligence system, population density, and wages.(5) The discussion will focus on the covariance and error-components model findings. Both models report substantively similar results in this study.

\section{TABULAR DATA OMITTED]}

The results indicate that for verbal, low threshold, and high threshold no-fault systems, auto insurance costs were on average significantly lower than tort when only bodily injury liability costs are considered. The estimate for verbal thresholds is $\$ 14.79$ lower than tort and that for low threshold states is $\$ 14.77$ less than tort, per earned car year. The high threshold states have estimated costs on average of $\$ 7.87$ less than tort.

The finding of lower costs under low- versus high-threshold systems is unanticipated. There is considerable heterogeneity within each class. Special provisions in "out-of-balance" no-fault law might result in particular no-fault benefits in high threshold states exceeding the benefits in lowthreshold states, despite the higher threshold.(6)

Estimated costs for optional add-on and compulsory add-on are greater than the tort system, although the differences are not statistically significant. The covariance model shows somewhat larger savings for each of the no-fault systems. The relative ranking is consistent with the error components model. These findings are as predicted, since the nature of no-fault is to preclude lawsuits.

The second stage of the analysis includes all bodily injury related costs including bodily injury liability, medical payments, uninsured motorist, and personal injury protection. These results are presented in Table 2. The OLS findings show considerably higher estimated costs in verbal, high threshold, optional add-on and compulsory add-on states than in tort. However, the apparent cost 
differentials associated with OLS disappear under the covariance and error components analyses. The covariance and error components results indicate that although no-fault systems have higher estimated costs than tort, only the estimate for compulsory add-on is highly significant, with an estimated cost of $\$ 35.73$ to $\$ 53.90$ higher than tort. The estimated coefficient for high threshold using error components suggests a higher cost of $\$ 12.37$ compared with the tort system, and is significant at the .10 level. The covariance estimate of $\$ 6.49$, however, is not statistically significant.

\section{Conclusions}

This study considers the magnitude of automobile insurance losses under various reparations systems. The findings show that states with verbal, low threshold, and high threshold no-fault law have lower bodily injury liability loss costs. Consistent with conventional wisdom, states with the least expensive bodily injury liability costs are those with verbal threshold no-fault laws. When total bodily injury related loss costs are considered, the cost advantage of no-fault systems disappears. After controlling for extraneous influences, total bodily injury related loss costs on average were not less under no-fault systems than the tort system.

These results suggests increase in first-party personal injury protection costs under no-fault on average were large enough to offset the reduction in liability costs, even in states with high monetary and verbal thresholds. Compulsory add-on, which combines higher costs of first-party insurance with unrestricted tort liability, appears to have been the most expensive system. These results must be interpreted with some caution given the possibility of selection bias. Some states could have changed from a tort to a no-fault system to curb escalating insurance costs. If states adopting no-fault had higher costs prior to no-fault adoption which cannot be explained by comparative negligence, wages, or population density, the omitted factors will influence the coefficient estimates of the no-fault dummy variables. To provide come insight into this issue, models also were estimated for the percentage change in bodily injury or total costs as the dependent variable. The independent variables were percentage change in hourly wages, population density, no-fault and comparative negligence dummies; an additional variable captured the possible transition effects during the year that no-fault was adopted or changed. Neither the bodily injury nor total cost regression had very much explanatory power, and the results provided no evidence that growth rates in loss costs were lower in no-fault states. Nonetheless, the possibility of selection bias remains a concern which future research might resolve. Finally, the models estimated are admittedly simple. While this might increase the likelihood of omitted variable bias, the inclusion of additional control variables to reflect numerous factors that might effect costs could raise endogeneity issues and increase the likelihood of problems with multicollinearity.

(1) A table indicating the month and year of tort and no-fault system changes for the 50 states is available for review by interested researchers. The data analyzed in this study are also available upon request. (2) The \$1,000 threshold is concern with Smith (1989). Although the threshold level would appear to be a continuous variable, the threshold level normally remains unchanged for several or more years. (3) A number of possible independent variables were considered and rejected due to unavailability of data. Some alternative independent variables were tested. For example, daily hospital costs (to the hospital) was substituted for manufacturing wages in the cost regressions to test the model's robustness. The qualitative implications remain unchanged; 
bodily injury costs remain less expensive under low threshold, high threshold and verbal nofault, however these cost savings are not present when total system costs are incorporated in the analysis. However, both verbal and high threshold systems appear more expensive than tort with this model. The daily hospitals costs coefficient was positive and highly significant in both regressions. (4) A covariance model treats loss costs as a function of the particular state (class) and the level of each of exogenous variable, where the data transformed into differences from the unit mean and least squares is applied to the transformed data without an intercept term. Because the wage variable effectively captures the trend in costs (by state) overtime, the simultaneous inclusion of these time dummies and wages generates excessive collinearity problems. In addition to the covariance model, the cost findings using the Fuller and Battese (1974) (crosssection and time effects) error components model are reported. If the random effects are normally distributed, the error components model can be shown to be more efficient than the covariance model, while giving unbiased and consistent parameter estimates provided that the random effects are uncorrelated with the other regressors (Pindyck and Rubinfield, 1981). The covariance and error components models imply different assumptions. The covariance model applies if inferences are made about specific cross-sectional units in a study (Hsiao, 1986). The error components model pertains if the inferences are made about the population of all classes. The two models sometimes produce substantially different empirical results (Hsiao, 1986). To allow for serial correlation in the disturbances in the covariance models, the parameter estimates were obtained assuming a first-order autoregressive process. First, the individual unit mean was subtracted from each observation for both the dependent and independent variables. Next, the autocorrelation coefficient was determined for each cross-sectional unit using GLS, and the serial correlation was eliminated. The covariance method was then applied to the transformed model (see Hsiao, 1986). The error components model assumes that the correlation of successive residuals is constant and independent of the period of time between disturbance terms (Pindyck and Rubinfield, 1981). (5) The Pearson correlation coefficients of the independent variables indicate that the independent regressors appear free of significant collinearity problems. Regressions with fewer no-fault dummy variables yield comparable results to those reported in Tables 1 and 2. The full correlation results are available from the authors. (6) For example, Georgia and Kansas are both low threshold states with $\$ 500$ thresholds (during the analysis period). However, Georgia limits benefits to $\$ 5,000$ and Kansas has an overall limit of $\$ 28,925$. On the other hand, Utah's threshold was $\$ 3,000$ (unit 7/86) and is classified as a high threshold state even though its overall benefit limit was \$14,180 in 1987.

Reference

Compilation, Automobile Liability Experience, 1971-1985, (New York: Insurance Services Office).

Flanigan, George B., Joseph E. Johnson, Daniel T. Winkler, and William Ferguson, 1989, Experience from Early Tort Reform: Comparative Negligence Since 1974, Journal of Risk and Insurance, 56: 525-34.

Fuller, Wayne A. and George E. Battese, 1974, Estimation of Linear Models with Crossed-Error Structure, Journal of Econometrics, 2: 67-78. 
Harrington, Scott, 1987, A Note on the Impact of Auto Insurance Rate Regulation, The Review of Economics and Statistics, March: 166-70.

Hsiao, Cheng, 1986, Analysis of Panel Data, Econometric Society monographs no. 11, (Cambridge: Cambridge University Press). J

ohnson, Joseph E., George B. Flanigan, and James K. Weeks, 1983, An Empirical Investigation of the Cost of Adopting No-Fault Insurance Systems, Journal of Insurance Regulation, 2: 168-75.

Kimball, Spencer L., 1985, The Context of No-Fault,' Journal of Risk and Insurance, 52: 66366.

O'Connell, Jeffrey and Robert H. Joost, 1986, Giving Motorists a Choice Between Fault and NoFault Insurance, Virginia Law Review, 72: 61-89.

Pindyck, Robert S. and Daniel L. Rubinfield, 1981, Econometric Models and Economic Forecasts, (New York: McGraw-Hill Inc.).

Smith, Brian W., 1989, Reexamining the Cost Benefits of No-Fault, CPCU Journal, March: 2836.

Todd, Jerry D., 1976, The Costing of No-Fault Automobile Insurance, Journal of Risk and Insurance, 43: 432-43.

U.S. Dept. of Transportation, 1985, Compensating Auto Accident Victims: A Followup Report on No-Fault Auto Insurance Experience, 18. 